\title{
SciDoc
}

Infer, Interpret \& Inspire Science

International Journal of Dentistry and Oral Science (IJDOS)

ISSN: $2377-8075$

\section{Single Tooth Replacement in Middle Aged Adults - A Retrospective Study}

Research Article

Gokul Gunasekaran ${ }^{1}$, V. Ashok ${ }^{2 *}$, Srirenga Lakshmi ${ }^{3}$

${ }^{1}$ Saveetha Dental College and Hospitals, Saveetha Institute of Medical and Technical Sciences, Saveetha University, Chennai, India.

${ }^{2}$ Professor and Head, Department of Prosthodontics, Saveetha Dental College and Hospitals, Saveetha Institute of Medical and Technical Sciences, Saveetha University, Chennai, 600077, India.

${ }^{3}$ Senior Lecturer, Department of Orthodontics, Saveetha Dental College and Hospitals, Saveetha Institute of Medical and Technical Sciences,

Saveetha University, Chennai, 600077, India.

Abstract

The choice between several treatment options for replacing a single missing tooth is influenced by clinical, dentist- and patientimmanent factors. This study aimed to determine the prevalence of age distribution and gender of the patient choosing Fixed Partial Denture (FPD) or Implant for single tooth replacement. The study compares the different treatment modalities (FPD or implant) for single tooth replacement of 461 patients records by comparison of the age group, gender and type of replacement which was obtained from the dental records at the private hospital. The analysis of the data gave more numbers of patients choosing FPD for the replacement of anterior teeth and lower posteriors for implants. The final choice between FPD or implant depended on several factors which affected the decision making; among these is cost and patients' awareness of the different treatment options. FPD is more opted for anteriors among the study population. More awareness on other treatment options for single tooth replacement must be made based on importance and advantages.

Keywords: Middle Age; Prosthesis; Single Tooth; Treatment Options.

\section{Introduction}

Replacement of missing teeth has become one of the most important esthetic and functional needs for patients visiting a dental clinic. The types of treatment modalities available for replacing a single missing tooth are removable partial denture, fixed partial denture or dental implant. Each modality is a possible treatment option and has its own advantages and disadvantages [1]. There are several factors affecting the final treatment decision regarding the replacement of a missing tooth, these factors are case dependent. In many cases if more than one treatment option is possible, the final replacement depends on the patient's decision or economic status or influenced by the patient's gender, age, public awareness and patient's knowledge. Therefore, it is important to understand the patient's needs and demands to determine the kind of treatment that ensures the patient is satisfied with the dental service provided. In many cases the cost of the treatment is considered as a major determinant and ahead of oral health status and patient preference. Pain and dental phobia are considered as important factors as well and they might affect the patient's decision not to receive treatment at all $[2,3]$. Accessibility which highlights important differences between people like a particular form of prosthetic treatment may be equally available to young and old patients, but the latter may find that the effort needed to seek out that treatment is just too great [4]. Treatment decisions cannot be performed depending on the basis of clinical examination or a dentist's opinion alone, but should be discussed in close consultation with patients [5]. In clinical decision making, dentists routinely choose between alternative treatments such as crown vs. amalgam/composite buildup; root canal treatment vs. extraction; fixed bridge vs. removable partial denture; and periodontal treatment vs. extraction. A number of clinical and patient factors can influence the dentist's choice of treatment in these situations. However, little is known about their relative importance. To ad-

\section{*Corresponding Author:}

V. Ashok,

Professor and Head, Department of Prosthodontics, Saveetha Dental College and Hospitals, Saveetha Institute of Medical and Technical Sciences, Saveetha University, Chennai, 600077, India.

E-mail: ashok@saveetha.com

Received: November 10, 2020

Accepted: December 15, 2020

Published: December 18, 2020

Citation: Gokul Gunasekaran, V. Ashok, Srirenga Lakshmi. Single Tooth Replacement in Middle Aged Adults - A Retrospective Study. Int J Dentistry Oral Sci. 2020;7(12):1271-1274. doi: http://dx.doi.org/10.19070/2377-8075-20000251

Copyright: V. Ashok ${ }^{\circ} 2020$. This is an open-access article distributed under the terms of the Creative Commons Attribution License, which permits unrestricted use, distribution and reproduction in any medium, provided the original author and source are credited. 
dress this issue, a list of clinical (e.g., periodontal status and caries rate) and patient (e.g., cost and patient preference) factors possibly influencing the choice of treatment was developed for each pair of services [6]. Decision making style was associated with service provision [7]. The term 'need' is commonly used to describe the amount of treatment that dentist's judge their patients ought to have, whilst 'demand' refers to the treatment requested by the patients themselves [8]. Most studies of prosthetic need and demand showed that the former is larger than the latter [9]. Other factors like the dentists, their particular skills, their accessibility to the public and the economic realities of the community in which they practise can affect the decision in choosing the treatment in addition to the attitudes of people towards different forms of treatment. These attitudes are influenced by such matters as education, personal finance, and cultural background [10].

Previously our team had conducted numerous clinical trials [1117] and lab studies [18-22] and in-vitro students [23-25] over the past 5 years. Now we are focussing on epidemiological surveys. The idea for this survey stemmed from the current interest in our community.

Despite the widespread concern in health care literature with patients' satisfaction, there has been no clear definition of that theory or the systematic consideration of its determinants and consequences. The replacement of a missing tooth by any of the prosthesis modalities occupies a major portion of the average restorative and prosthodontic practice. Treatment options keep changing due to continuous development in the field of dentistry $[26,27]$. This study aimed to determine the prevalence of age distribution and gender of the patient choosing Fixed Partial Denture (FPD) or Implant for single tooth replacement among middle aged adults in Chennai.

\section{Materials and Methods}

This retrospective study was conducted in a university setting. Data chosen for evaluation were patients who reported to a private hospital for dental treatment.The details of the patients were obtained from analysis of 86,000 patients from June, 2019 to March, 2020 from the outpatient record of patients visited for dental treatment, for the purpose of preservation and efficient analysis of the patients details including intraoral and extra oral pictures and treatments being done, which is maintained in a confidential manner. These serve as records for the retrospec- tive studies. The study was conducted after getting ethical approval from the Institutional Ethical Committee (Ethical approval number: SDC/SIHEC/2020/DIASDATA/0619-0320). To minimise sampling bias all data were included. The inclusion criteria included patients who required single missing tooth replacement and between the age group 35-55. The exclusion criteria included patients with multiple missing teeth, below 35 and above 55 years of age. Data was downloaded from the outpatient records and imported to Excel. Data which was not required were excluded and an Excel tabulation was done. The Excel sheet was then imported to SPSS and results were obtained in the form of graphs and tables. The advantages of the study included easy accessibility and availability of the required data and drawback was the available data was not location specific and belonged to different ethnicity.Independent variables that were included in the study age, gender, sextant. The dependent variable included treatment modality. The correlation and association between the variables were analysed and assessed using this test.

\section{Results And Discussion}

The study included 461 participants who had undergone prosthetic replacementment. Of the participants 219 were females and 242 were males. The highest number of FPDs (117) were inserted in the 30-36 age group while the highest number of implants(63) were placed in the 37-43 age group.FPDs were preferably placed in sextant 2 while implants were placed in sextant 4/ sextant 6. From Figure 1, FPDs were more preferred by males and females when compared to implants. However, it was not statistically significant. (Chi-square test; $\mathrm{p}=0.581$ - not significant). From Figure 2, FPDs were more preferred by all age groups when compared to implants but were found to be considerably higher among 37-43 and 44-50 age groups.It was statistically significant. (Chi-square test; $\mathrm{p}=0.00$ - highly significant). From Figure 3, FPDs were more preferred by all sextants when compared to implants but were found to be considerably higher among sextants 4 and 6. It was statistically significant. (Chi-square test; $\mathrm{p}=0.00$ - highly significant).

The study helps to find the number of patients undergoing implants and FPD. The study helps to find the number of patients undergoing implants and FPD for single tooth replacement . Another Study reported that dental implants can provide various clinical and quality of life advantages compared to FPDs and implants but it is more expensive when compared to other single

Figure 1. The bar graph portrays the comparison of gender and treatment modalities for replacement of single missing tooth where $\mathrm{X}$-axis represents gender and $\mathrm{Y}$-axis represents the number of patients for single tooth replacement. FPD (blue) was more preferred by males and females when compared to Implants (green) but the differences were not statistically significant (Chi-Square Test; $p$ value-0.581-(>0.05, hence statistically, not significant)).

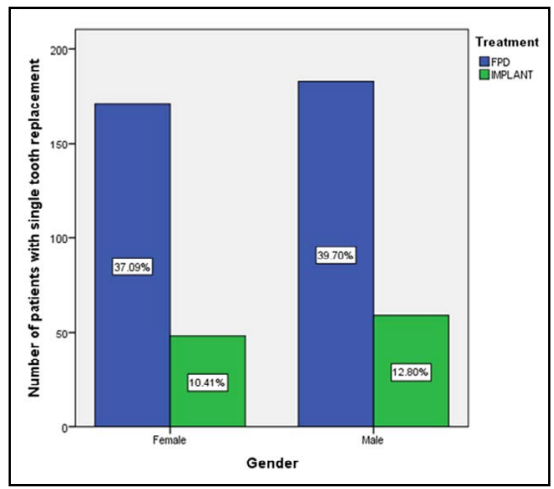


Figure 2. The bar graph portrays the comparison of age groups and treatment modalities for the replacement of missing tooth where $\mathrm{X}$-axis represents age groups and $\mathrm{Y}$-axis represents the number of patients for single tooth replacement . FPD (blue) was more preferred by all age groups when compared to Implants (green) and the results were statistically significant. (Chi-Square Test; $\mathrm{p}$ value- $0.00(<0.05$ hence statistically, significant)).

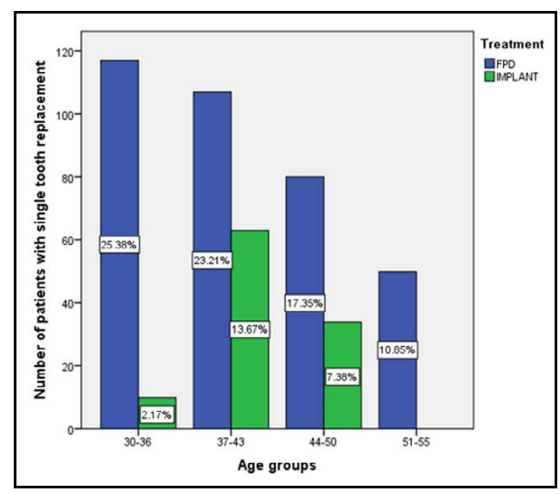

Figure 3. The bar graph portrays the comparison of sextants and treatment modalities for the replacement of missing tooth where $\mathrm{X}$-axis represents sextant and $\mathrm{Y}$-axis represents the number of patients for single tooth replacement. FPD (blue) were more preferred in all sextants when compared to implants (green) but were found to be considerably higher among sextants 4 and 6 and were found statistically significant. (Chi-Square Test; p value- $0.00(<0.05$ hence statistically, significant)).

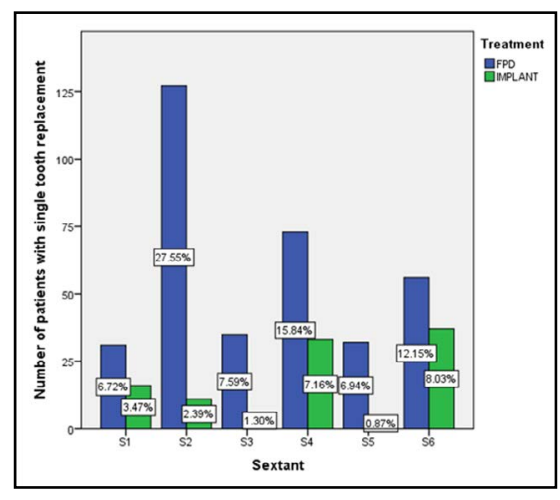

tooth replacement modalities [28]. A reason for FPDs to be chosen by patients instead of implants may be due to higher number of visits and time period when compared to implants [29].

The majority number of patients who chose single tooth replacement were males and FPDs were the most preferred treatment of choice.Rarely does a patient desire or accept a removable partial prosthesis as a substitute for a single missing tooth especially anterior tooth [30]. Another study stated that the cost was an important factor for choosing the preferred replacement modality especially for implant replacement [31]. Patients as well as dentists preferences regarding treatment options depend on several factors such as rejection to surgical procedures, treatment duration, cost, conditions of adjacent teeth or dental phobia. For a true economic evaluation, cost and benefits of different therapies are usually compared. The clinical outcome (benefit) in this study was 'single-tooth replacement. Additional research is needed to assess lifetime costs that include initial and maintenance costs, and future replacement costs associated with various alternatives. Besides, most of the reported studies compared FPD cost with other modalities [32]. Many factors must be considered when choosing between different treatment options for the replacement of a single-tooth, often the bias of the dentist plays a role rather than objective appraisal of the treatment options.Patient awareness of the advantages and disadvantages of different treatment modalities is very important for decision making, therefore there are many factors that make single-tooth replacement one of the most challenging restorations in dentistry.

\section{Conclusion}

Within the limitations of the study, it was found that FPD was preferred among the middle aged adults when compared to implants for single tooth replacement. The preferences for FPD and Implants were found to be slightly higher among males when compared to females. Most of the patients preferred FPD in the anterior teeth region and implants in the posterior teeth region. Therefore, more awareness and knowledge on other advanced treatment modalities and its benefits must be made known to patients prior to any prosthetic rehabilitation.

\section{Acknowledgement}

The authors thank Saveetha Dental College for constant support in providing the data for analysis.

\section{References}

[1]. Christensen GJ. Elective vs. mandatory dentistry. J Am Dent Assoc. 2000 Oct;131(10):1496-8. PMID: 11042991.

[2]. Shillingburg HT, Hobo S, Whitsett LD, Jacobi R, Brackett SE. Fundamentals of fixed prosthodontics. Quintessence Publishing Company; 1997 Jan.

[3]. Kvale G, Berggren U, Milgrom P. Dental fear in adults: a meta-analysis of behavioral interventions. Community Dent Oral Epidemiol. 2004 Aug;32(4):250-64. PMID: 15239776.

[4]. Bianco G, Di Raimondo R, Luongo G, Paoleschi C, Piccoli P, Piccoli C, Rangert B. Osseointegrated implant for single-tooth replacement: a retro- 
spective multicenter study on routine use in private practice. Clin Implant Dent Relat Res. 2000;2(3):152-8. PMID: 11359260.

[5]. Maizels J, Maizels A, Sheiham A. Sociodental approach to the identification of dental treatment-need groups. Community Dent Oral Epidemiol. 1993 Dec;21(6):340-6. PMID: 8306610.

[6]. Grembowski D, Milgrom P, Fiset L. Factors influencing dental decision making. J Public Health Dent. 1988 Summer;48(3):159-67. PMID: 3045303.

[7]. Brennan DS, Spencer AJ. Factors influencing choice of dental treatment by private general practitioners. Int J Behav Med. 2002;9(2):94-110. PMID: 12174535 .

[8]. Öwall B, Käyser AF, Carlsson GE. Prosthodontics: principles and management strategies. Mosby; 1996.

[9]. Wiens JP, Priebe JW, Curtis DA, editors. Journal of Prosthodontics on Complete and Removable Dentures. John Wiley \& Sons; 2018 Feb 12

[10]. Davenport JC, Davenport JC, Basker RM, Heath JR. A clinical guide to removable partial denture design. British Dental Association; 2000.

[11]. Jyothi S, Robin PK, Ganapathy D. Periodontal health status of three different groups wearing temporary partial denture. Research Journal of Pharmacy and Technology. 2017 Dec 1;10(12):4339-42.

[12]. Jain AR, Nallaswamy D, Ariga P, Ganapathy DM. Determination of correlation of width of maxillary anterior teeth using extraoral and intraoral factors in Indian population: A systematic review. World J Dent. 2018 Jan;9:68-75.

[13]. Duraisamy R, Krishnan CS, Ramasubramanian H, Sampathkumar J, Mariappan S, Navarasampatti Sivaprakasam A. Compatibility of Nonoriginal Abutments With Implants: Evaluation of Microgap at the Implant-Abutment Interface, With Original and Nonoriginal Abutments. Implant Dent. 2019 Jun;28(3):289-295. PMID: 31124826.

[14]. Selvan SR, Ganapathy D. Efficacy of fifth generation cephalosporins against methicillin-resistant Staphylococcus aureus-A review. Research Journal of Pharmacy and Technology. 2016 Oct 28;9(10):1815-8.

[15]. Ganapathy D, Sathyamoorthy A, Ranganathan H, Murthykumar K. Effect of Resin Bonded Luting Agents Influencing Marginal Discrepancy in All Ceramic Complete Veneer Crowns. J Clin Diagn Res. 2016 Dec;10(12):ZC67ZC70. PMID: 28209008.

[16]. Subasree S, Murthykumar K. Effect of aloe vera in oral health-A review. Research Journal of Pharmacy and Technology. 2016 May 1;9(5):609.

[17]. Ranganathan H, Ganapathy DM, Jain AR. Cervical and Incisal Marginal Discrepancy in Ceramic Laminate Veneering Materials: A SEM Analysis. Contemp Clin Dent. 2017 Apr-Jun;8(2):272-278. PMID: 28839415.

[18]. Vijayalakshmi B, Ganapathy D. Medical management of cellulitis. Research Journal of Pharmacy and Technology. 2016 Nov 28;9(11):2067-70.

[19]. Ganapathy DM, Kannan A, Venugopalan S. Effect of coated surfaces influ- encing screw loosening in implants: A systematic review and meta-analysis. World Journal of Dentistry. 2017 Nov; 8(6): 496-502.

[20]. Ashok V, Suvitha S. Awareness of all ceramic restoration in rural population. Research Journal of Pharmacy and Technology. 2016 Oct 28;9(10):1691-3.

[21]. Ashok V, Nallaswamy D, Benazir Begum S, Nesappan T. Lip Bumper Prosthesis for an Acromegaly Patient: A Clinical Report. J Indian Prosthodont Soc. 2014 Dec;14(Suppl 1):279-82. PMID: 26199531.

[22]. Venugopalan S, Ariga P, Aggarwal P, Viswanath A. Magnetically retained silicone facial prosthesis. Niger J Clin Pract. 2014 Mar-Apr;17(2):260-4. PMID: 24553044

[23]. Kannan A, Venugopalan S. A systematic review on the effect of use of impregnated retraction cords on gingiva. Research Journal of Pharmacy and Technology. 2018 May 30;11(5):2121-6. h

[24]. Basha FY, Ganapathy D, Venugopalan S. Oral hygiene status among pregnant women. Research Journal of Pharmacy and Technology. 2018 Jul 31;11(7):3099-102.

[25]. Ajay R, Suma K, Ali SA, Kumar Sivakumar JS, Rakshagan V, Devaki V, Divya K. Effect of Surface Modifications on the Retention of Cement-retained Implant Crowns under Fatigue Loads: An In vitro Study. J Pharm Bioallied Sci. 2017 Nov;9(Suppl 1):S154-S160. PMID: 29284956.

[26]. Garcia LT, Cronin RJ Jr. The partially edentulous patient: fixed prosthodontics or implant treatment options. Tex Dent J. 2003 Dec;120(12):1148-56. PMID: 14740394.

[27]. Salinas TJ, Block MS, Sadan A. Fixed partial denture or single-tooth implant restoration? Statistical considerations for sequencing and treatment. J Oral Maxillofac Surg. 2004 Sep;62(9 Suppl 2):2-16. PMID: 15332176.

[28]. Christensen GJ. Three-unit fixed prostheses versus implant-supported single crowns. J Am Dent Assoc. 2008 Feb;139(2):191-4. PMID: 18245688.

[29]. Brägger U, Krenander P, Lang NP. Economic aspects of single-tooth replacement. Clin Oral Implants Res. 2005 Jun;16(3):335-41. PMID: 15877754.

[30]. Walmsley D. Book reviewFundamentals of Fixed Prosthodontics 4th edn. By Herbert T. Shillingburg HT and colleagues. London: Quintessence Books, 2012. Dental Update. 2012; 592-592.

[31]. Tepper G, Haas R, Mailath G, Teller C, Zechner W, Watzak G, et al. Representative marketing-oriented study on implants in the Austrian population. I. Level of information, sources of information and need for patient information. Clin Oral Implants Res. 2003 Oct;14(5):621-33. PMID: 12969367.

[32]. Al-Quran FA, Al-Ghalayini RF, Al-Zu'bi BN. Single-tooth replacement: factors affecting different prosthetic treatment modalities. BMC Oral Health. 2011 Dec 21;11:34. PMID: 22188872. 